\title{
A Participação da Sociedade Civil nos Conselhos Municipais em Juazeiro - Bahia: Prática de Cidadania
}

\author{
Iracema Uchôa Batista ${ }^{1}$; Deise Cristiane do Nascimento ${ }^{2}$
}

\begin{abstract}
Resumo: Resumo: O objetivo deste artigo é estudar artigos científicos sobre os Conselhos Municipais e Participação Popular no Brasil e estudo junto aos Conselhos municipais de Juazeiro-Bahia. Foi efetuada uma revisão bibliográfica nas bases de dados Scientific Eletronic Library online (SCIELO), LILACS, Google acadêmico, Biblioteca Virtual sobre Corrupção (BVC) da Controladoria Geral da União - CGU, e o banco de dados de teses CAPES (Coordenação de Aperfeiçoamento de Pessoal de Nível Superior). Esse estudo buscou responder à seguinte questão: qual a prática de cidadania nos conselhos municipais em Juazeiro-Bahia? Os conselhos municipais de juazeiro-Bahia, são espaços de participação de suma importância para o debate da democracia e o desenvolvimento das politicas publicas. Os resultados são importantes para que gestores, conselheiros, sociedade civil e pesquisadores analisarem e aprimorar o conhecimento sobre os conselhos municipais de Juazeiro-Bahia.
\end{abstract}

Palavras-chave: Conselhos Municipais, Participação Social, Cidadania.

\section{The participation of civil society in the Municipal Councils in Juazeiro - Bahia : Citizenship Practice}

\begin{abstract}
The purpose of this article is to study scientific articles on the Municipal Councils and People's Participation in Brazil and study with municipal Juazeiro -Bahia Councils. a literature review in the databases Scientific Electronic Library Online was performed ( SCIELO ), LILACS, Google Scholar , Virtual Library on Corruption ( BVC) of the Comptroller General - CGU, and the database of CAPES theses ( Improvement Coordination Higher Education personnel ). This study sought to answer the following question: what is the practice of citizenship in the municipal councils in Juazeiro - Bahia? The municipal councils of jujube -Bahia, are spaces of participation of paramount importance to the discussion of democracy and the development of public policies. The results are important for managers, directors, civil society and researchers analyze and improve knowledge of the municipal councils of Juazeiro -Bahia
\end{abstract}

Keywords: Municipal Councils, Social Participation, Citizenship.

\section{Introdução}

A partir da Constituição da República Federativa do Brasil, em 1988, cidadãos e sociedade civil organizada passam a ter direito de participar diretamente em processos decisivos referentes ao Estado brasileiro (AZEVEDO, 2005).

\footnotetext{
${ }^{1}$ Universidade Federal do Vale do São Francisco/Curso de Pós-Graduação em Gestão Pública Municipal/ BA - Brasil. E-mail: iracemauchoa@yahoo.com.br

${ }^{2}$ Universidade Federal do Vale do São Francisco/Curso de Pós Graduação em Gestão Pública Municipal/ BA - Brasil
} 
Nessa concepção, a gestão das políticas públicas proporciona melhor diálogo entre atores e organizações que, uma vez juntos em diversos territórios de interesse coletivo, podem facilitar movimentos interativos e popular na correlação entre governo e sociedade civil.

No Brasil a participação democrática, tem como referência os movimentos sociais da área da educação e saúde, que, pelo menos desde 1936, participam da formulação de políticas públicas nacionais. Os movimentos sociais brasileiros pela participação popular de políticas públicas ocorreram apenas com a promulgação da Constituição Federal (BRASIL, 1988).

Conforme Tatagiba, 2005, os Conselhos Municipais representa uma das principais práticas de democracia atuante no Brasil moderno. Hoje na maioria dos municípios brasileiros, organizados desde o nível federal, defendendo uma grande gama de questões como: educação, saúde, segurança, moradia, meio ambiente, transporte, cultura, dos direitos do idoso, da criança e adolescente, da juventude, do deficiente, entre outros, retrata uma vitória inquestionável na perspectiva da criação de uma institucionalidade democrática entre a população.

Sua importante inovação expressa em assegurar na apuração e do estabelecimento do consenso entre governo e sociedade, em canais populares e diversificados, como requisito para uma aplicação mais justa e eficiente dos recursos públicos (TATAGIBA, 2005).

Conforme Tatagiba, 2005, os conselhos administradores, no âmbito participativo e decisório, proporcionam experiências de convivência democrática, tanto para os atores da comunidade civil quanto os do Estado. A realidade dessas instâncias confirma a obrigação para que o governo dê divulgação a suas ações, mostre contas, exponha fundamentos que balizam acordos, mas também para que a sociedade civil se capacite para essa atuação.

Segundo Andrade e Valtsman, 2013, ainda que os conselhos em acordo retratem um aperfeiçoamento da soberania popular, ao integrarem representantes da sociedade civil na gestão das políticas públicas nos três níveis de governo, fortalecendo uma rede de relação entre atores oficiais e não oficiais e propiciando modernas práxis para a solução de questões, as observações de experiências locais visam inúmeras instigações. Em diversas situações, a presença da sociedade civil tem se restringido a uma aceitação acrítica de planos e projetos governamentais.

$\mathrm{Na}$ verdade, tem se mencionado que a intervenção de partidos políticos locais pode limitar a liberdade da participação da sociedade civil. 
Id on Line Revista Multidisciplinar e de Psicoloqia

Id on Line Multidisciplinary Journal and Psycology

A questão norteadora adotada para este estudo foi: qual a participação da sociedade civil nos conselhos municipais em Juazeiro - Bahia, esse estudo buscou responder à seguinte questão: qual a prática de cidadania nos conselhos municipais em Juazeiro-Bahia? Diante disso objetivou-se analisar artigos científicos sobre os Conselhos Municipais e Participação Popular no Brasil e observação junto aos Conselhos municipais de Juazeiro-Bahia.

Assim pretende-se averiguar como se dá a inserção dos representantes da sociedade civil, se por indicação ou escolha de cada segmento e se os conselheiros recebem formação para atuar com responsabilidade e interesse no coletivo e ainda se participam das reuniões, das discussões, em fim se estão tendo uma atuação cidadã consciente.

Este estudo observa e debate alguns desafios para que a potencialidade se exerça tendo como suporte os conselhos municipais do município de Juazeiro-Bahia.

\section{Metodologia}

Trata-se de estudo de revisão bibliográfica e qualitativa realizada em bases de dados disponíveis na internet. Foram utilizados os descritores cadastrados no sistema Descritores em ciências da Saúde (DeCS), utilizados pela Bireme. Os descritores usados foram: Conselhos municipais, Participação Social, Cidadania. Complementando-se à procura das palavras-chave de conceito semelhante ao descritor no propósito de descobrir pesquisas que poderiam não estar usando descritores normatizados (Cidadania, conselhos). Foi realizada também uma observação junto aos Conselhos municipais de Juazeiro-Bahia.

Os critérios utilizados para seleção foram: artigos publicados em periódicos nacionais, considerando materiais publicados a partir de 1988, ano da promulgação da Constituição Federal de 1988 (BRASIL, 2016), no idioma português, que tivessem relação com o objetivo desse estudo e que estivessem disponíveis em uma das seguintes bases de dados: Scientific Eletronic Library online (SCIELO), LILACS, Google acadêmico, Biblioteca Virtual sobre Corrupção (BVC) da Controladoria Geral da União - CGU, e o banco de dados de teses CAPES (Coordenação de Aperfeiçoamento de Pessoal de Nível Superior), no mês de maio de 2016. 
A primeira busca nas fontes resultou no diagnóstico de 10 artigos pelo (LILACS) e Scielo. O critério para seleção foi leitura dos resumos e que no final foram selecionados 05 artigos.

Foram selecionados primeiramente artigos publicados que descrevem estudos de casos, reflexões, sobre os conselhos municipais, pois o objetivo principal da revisão foi analisar os conselhos gestores no Brasil.

O levantamento foi realizado pelo acesso online, nas bases de dados selecionados e com base nos parâmetros de inclusão. A apresentação final desta revisão foi composta por seis artigos do LILACS e Scielo.

A análise dos materiais, a temática dos artigos foi relacionada em um quadro contendo: nome do autor (es), ano de publicação, revista e país de publicação e método de pesquisa. E por fim, apresentação dos resultados e discussão dos dados adquiridos e observados de maneira descritiva, proporcionando e contribuindo com elementos de estudo ao pesquisador sobre a Participação Cidadã da Sociedade nos Conselhos Municipais em Juazeiro-Bahia.

\section{Fundamentação Teórica}

Com a promulgação da Constituição Federal de 1988 ampliou-se os espaços de participação da sociedade civil nas políticas públicas e os Conselhos Municipais tornaram--se um dos principais instrumentos de viabilidade dessa participação popular.

Estudos revelam que a participação da sociedade nas decisões políticas do país sempre existiu, embora muitos achem que a população brasileira sempre foi apática as decisões do Estado. Contudo a história política brasileira demonstra atitudes e comportamento do povo organizado lutando pelos seus direitos, manifestando suas insatisfações. É certo que essa luta tem relação com o momento histórico e político das organizações e movimentos e depende da relação entre governos e sociedade.

Conforme Simões, 2007, a participação político brasileiro tornou-se realidade, a sociedade civil organizada pode participar da implantação e gestão das políticas públicas, assumindo as obrigações nas deliberações públicas. A "Constituição Cidadã" como ficou conhecida proporcionou a sociedade de recursos e da expansão de espaços democráticos. 
Id on Line Revista Multidisciplinar e de Psicoloqia

Id on Line Multidisciplinary Journal and Psycology

Com base na literatura pesquisada estas obedeceram aos parâmetros de inclusão preestabelecidos e consequentemente foi efetuada uma exposição geral dos artigos classificados.

Dos artigos analisados, três foram estudos de caso e um de revisão bibliográfica e um relato de experiência. Em relação aos artigos estudo de caso foram realizados nos Estados de Santa Catarina, Paraná e Rio de Janeiro.

Os artigos constatou-se que o tipo de estudo é baseado em análise qualitativa, publicados em Revistas de Administração, Cadernos EBAPE. BR, Psicologia em Estudo, Ciência \& Saúde Coletiva, Revista de Administração de Empresas.

A fim de mensurar e elucidar a questão norteadora a ser respondida foram relacionados para discussão, três classes, tratando questões sobre participação e controle social nos conselhos municipais. As categorias escolhidas foram: instrumentos e mecanismos de controle e gestão pelos conselhos municipais, participação democrática nos conselhos municipais, nortes para profissionais da psicologia que buscam atuar nas politicas públicas.

Quadro 1 - Estudos de caso sobre conselhos municipais

\begin{tabular}{|l|l|}
\hline Autor, ano de publicação, revista e país. & Sucinta apresentação sobre a metodologia e sobre a pesquisa \\
\hline $\begin{array}{l}\text { Kleba et. Al, 2015, Revista Administração } \\
\text { Pública - Brasil }\end{array}$ & $\begin{array}{l}\text { Estudo de caso enfatizando a realidade dos mecanismos de gestão } \\
\text { utilizados pelos conselhos municipais no município de Chapecó-SC. }\end{array}$ \\
\hline $\begin{array}{l}\text { Gomes, E.G.M. 2015, Cadernos } \\
\text { EBAPE.BR, 2016 - Brasil. }\end{array}$ & $\begin{array}{l}\text { Revisão bibliográfica sobre o potencial de controle social e } \\
\text { democrático dos conselhos gestores de políticas públicas. }\end{array}$ \\
\hline $\begin{array}{l}\text { Benelli, S.J; Rosa, A. da C. 2012, Psicologia } \\
\text { em Estudo - Brasil. }\end{array}$ & $\begin{array}{l}\text { Relato de experiência em dois conselhos municipais os quais } \\
\text { oferecem norte para profissionais de psicologia que buscam atuar no } \\
\text { âmbito das políticas públicas. }\end{array}$ \\
\hline $\begin{array}{l}\text { Andrade, G.R. B de; Vaitsman, J. 2013, } \\
\text { Ciência \& Saúde Coletiva - Brasil. }\end{array}$ & $\begin{array}{l}\text { Estudo de caso sobre a participação civil nos conselhos de saúde e de } \\
\text { políticas sociais no município de Piraí-RJ. }\end{array}$ \\
\hline $\begin{array}{l}\text { Tatagiba - 2005, Revista de Sociologia e e } \\
\text { Política - Brasil. }\end{array}$ & $\begin{array}{l}\text { Estudo de caso sobre participação democrática nos conselhos gestores } \\
\text { do Paraná, conselhos municipais de Curitiba e Maringá-PR. }\end{array}$ \\
\hline
\end{tabular}

Fonte: Scielo e Lilacs

A relevância da participação popular nas decisões políticas no âmbito federal, estadual e municipal teve sua alavancada através de vários dispositivos instituídos pela Constituição de 1988 e isso pode ser considerado como um grande avanço no sentido de permitir o envolvimento e a participação da sociedade civil. 
Conforme Kleba et. al (2015) os conselhos gestores de políticas públicas se instituem instâncias para articular a soberania participativa e, com isso, determinar em proteção dos interesses comunitários e do bem comum. A formação destes territórios públicos pode atingir níveis considerados de discussão e resoluções, quando se constitui a institucionalização de mecanismos a serem aplicados em seus métodos de gestão, com perspectivas a fortalecer as ações participativas, resolutivas e de controle social em face dos atos realizados.

Segundo Gomes (2015) estes espaços de discussões procura questionar sobre as diversas questões relacionadas às políticas públicas e o mesmo faz considerações a respeito da distinção entre "responsiveness" e "Accountability", tanto por parte da administração pública quanto por parte da sociedade, pois essa delegação é uma ligação determinada entre interesses e resultados, enquanto podemos admitir que o governo é responsivo, contudo, pode não ser emblemático se os resultados alcançados pelas politicas selecionadas não caminhar para os interesses dos representados.

Ou seja, a reciprocidade entre representação e responsividade somente aconteceria se o eleitor tivesse as informações necessárias para escolher a politica que realizasse seus interesses.

Em concordância com Gomes (2015) os conselhos tem vasto potencial para se tornarem instância de controle social democrático, principalmente por causa de seu caráter plural e determinante, ao contexto local e ao alvo setorial da política pública. Se alguns problemas de árdua superação, como os obstáculos relativos à eleição democrática dos conselheiros da sociedade civil ou à inadequação planejada do uso de mecanismos rigorosos de responsabilização dos gestores públicos.

Segundo Benelli e Rosa (2012) pelas análises criaram o tipo de "prefeiturização" dos conselhos municipais. Onde afirma que os conselhos disputa e luta com o poder público em áreas essenciais das politicas públicas de assistência e para infância, executando até mesmo, atribuições adicionais.

Tanto que os prefeitos acreditam que os conselhos retratam apenas uma reestruturação burocrática na gestão municipal e que não implicam reformas e modificações radicais nos moldes de gestão da coisa pública, boicotando o trabalho eficaz dos conselhos. Então, o psicólogo que está seduzido numa participação social critica necessita se equipar teoricamente, técnica e eticamente para integralizar os saberes de causa, as falhas acessíveis nos conselhos municipais. 
Conforme Andrade e Vaitsman (2013) o estudo verificou três aspectos referentes a participação da sociedade civil nos conselhos municipais em um município de pequeno porte sobre : os custos e incentivos à participação nos conselhos, a influência e as contribuições da participação para gestão das políticas sociais e para sociedade civil.

Detectaram que a participação para conselheiro é através de convite, porém alguns chegam de forma espontânea, por conta própria. Em virtude do grande aumento dos conselhos na cidade, tem casando a capacidade das organizações da sociedade civil em preencher os Conselhos com qualidade.

Os ganhos dos conselheiros é o conhecimento e o acesso às informações e isso acarreta no reconhecimento dos parceiros e da comunidade. O cargo de conselheiro agrega valor ao trabalho de liderança comunitária e membro sem fim lucrativo.

Conforme Andrade e Vaitsman (2013) os lideres comunitários optam pelos conselhos mais organizados, relacionados aos órgãos que tem um bom desempenho e capacidade de atender às demandas da população. Então, os setores mais problemáticos ou com politicas principiantes não atraem o interesse de líderes comunitários. Dessa maneira, os conselhos não têm projetado canais pelos quais o governo poderia identificar problemas urgentes ou aprimorar o desempenho de politicas com debilitado desempenho na cidade.

\section{Políticas Públicas e Contribuição na Gestão}

A consolidação no campo das políticas públicas se efetivou na última metade do século $\mathrm{XX}$, com uma teoria própria e instrumento crítico voltado para o entendimento de fatos de natureza político-administrativa. (SECCHI, 2012).

Conforme Secchi, 2012, as informações geradas na área de políticas públicas vêm sendo amplamente aplicado por pesquisadores, políticos e administradores que lidam com problemas públicos em diversos setores de intervenção e nas mais diferentes áreas: ciência política, sociologia, economia, administração pública, direito etc. Vêm sendo usado tanto com relação à implementação e a avaliação das políticas públicas, quanto no que diz respeito a abordagens que enfatizam o papel das ideias e do entendimento neste processo. E isso porque, conforme 
Id on Line Revista Multidisciplinar e de Psicoloqia

Id on Line Multidisciplinary Journal and Psycology

Faria (2003), as ideias e o conhecimento são primordiais para a percepção e elaboração de uma agenda de execução de políticas públicas, pois esta agenda tem um "ciclo de políticas públicas".

Segundo Souza, 2006, geralmente, compreendem-se Políticas Públicas como dispositivo ou conjunto de ação dos Governos, uma ação desenvolvida no propósito de confrontar um problema público (SECCHI, 2012). Pois ainda não existe um senso comum na literatura sobre o conceito ou descrição de Políticas Públicas, por este ser ainda um tema contemporâneo da ciência política.

Em concordância com Rodrigues, 2011, como um campo de estudo específico, podemos interpretar a Política Pública como a análise dessas ações governamentais (e não governamentais) e, quando preciso, propor alterações no decorrer dessas ações. A elaboração de políticas públicas estabelece programas e ações (o que fazer), metas e objetivos (a onde chegar) e planos de ação (como fazer) que devem produzir resultados ou transformações no mundo real. O planejamento de programas, ações, metas e objetivos constituem também objeto de estudo da própria Administração Pública, entendida como atividade do Estado que deve organizar o funcionamento dos serviços públicos prestados à sociedade.

Segundo Souza, 2006, alguns locais no campo da esfera pública são essenciais para a discussão, negociação e o processo de construção de uma política, dentre os quais podemos citar o Poder Executivo, o Poder Legislativo, Conselhos Gestores de Políticas Públicas, entre outros.

No âmbito do Poder Legislativo temos o Congresso Nacional, as Assembleias Legislativas e Câmara de Vereadores. Toda vez que uma política pública necessita de um substrato legal antes de sua execução ela terá que, necessariamente, passar pelo Poder Legislativo (SOUZA, 2006).

Outro exemplo é o Congresso Nacional que debate e discute algumas demandas em parceria com a sociedade, através dos portais da câmara e do senado, como os portais edemocracia (da Câmara dos Deputados) e-cidadania (do Senado Federal).

Outro lugar de negociação importante é o próprio Poder Executivo. Onde atuam diversos atores comprometidos com uma específica política pública: Ministérios, Secretarias, Profissionais de uma determinada área. Outro local que pode ter uma colaboração importante no debate e elaboração de políticas públicas são os Conselhos Gestores de Políticas Públicas. 
Id on Line Revista Multidisciplinar e de Psicoloqia

Id on Line Multidisciplinary Journal and Psycology

Conforme Souza, 2006 diversos estudiosos e pesquisadores da área de políticas públicas advertem para o fato de como tais políticas deve ser elaboradas atualmente com participação social, o que podemos chamar de Processos de Gestão Democrática.

Segundo Secchi, 2012, na política pública a Gestão democrática é de suma importância para o gestor em suas decisões, uma vez que no modelo de Gestão Democrática a sociedade civil organizada deve ser incentivada a participar do monitoramento e implantação de políticas públicas, incluindo aí o monitoramento e criação da política orçamentária com base no planejamento do governo que inclui o PPA (Plano Plurianual), LDO (Lei de Diretrizes Orçamentárias) e LOA (Lei Orçamentária Anual). É o que podemos definir de uma política de participação e controle social do processo orçamentário que deve ocorrer nas três esferas de governo: municipal, estadual e federal.

De acordo com Moroni, 2009 o PPA é fundamental ao planejamento das políticas públicas, pois, determinam, em linhas gerais, as perspectivas, os programas, os objetivos e as metas para os próximos quatro anos. A LDO discrimina os programas urgentes, as metas físicas e as regras gerais de como deverá ser elaborado o orçamento do próximo ano. A LOA é como e onde os recursos públicos serão aplicados, isto é, o orçamento público.

Segundo Norma Lacerda et.al. 2005, enfatiza a relevância para o planejamento de políticas públicas no contexto municipal o Plano Diretor, que deve servir de base para a execução dos programas de governo devendo ser reanalisado frequentemente.

O Plano Diretor objetiva regulamentar as ações dos agentes públicos e privados no processo de desenvolvimento municipal, podendo ser um importante mecanismo de planejamento se for capaz de reunir vários atores sociais. O seu maior desafio é a combinação das dimensões técnica e política: dimensão técnica, à medida que tem de ser fundamentado em análises embasadas em um conjunto informacional; dimensão política, uma vez que a sua criação constitui um espaço priorizado de negociação entre os atores sociais, enfrentando e articulando seus interesses. (LACERDA et al., 2005, p. 56).

Algumas ideias sobre políticas públicas: “a eficácia das políticas públicas depende do grau de eficiência da gestão, o que, por sua vez, implica não apenas a qualidade dos gestores para exercer seu ofício público, mas também um ambiente de atuação que favoreça a governança democrática e a responsabilização política” (RODRIGUES, 2011, p. 24). 
Id on Line Revista Multidisciplinar e de Psicoloqia

Id on Line Multidisciplinary Journal and Psycology

Para que as políticas públicas modifiquem uma sociedade é preciso: atores políticos com competência para identificar e analisar a realidade social, econômica e política em que convivem, além de negociar de maneira democrática com os diversos atores envolvidos no processo. "Tudo isso envolve habilidades para gerenciar complexidades (em cenários de incertezas e turbulência, por exemplo) e conseguir colaboração de todos os que estão envolvidos na criação de determinadas ações de governo" (RODRIGUES, 2011, p. 25).

A gestão de políticas públicas pode ser estruturada por meio de propostas de apreciações e interpretação também denominada como ciclo de políticas públicas (policy cycle). Esses projetos são estruturados em etapas continuas e interdependentes que vão desde a fase inicial de identificação do problema, até a elaboração de alternativas para o mesmo e criação da política pública: "para que o programa/política saia do papel, é preciso interpretar o ambiente para planejar/organizar as ações, decidir sobre os benefícios/serviços que se pretende implementar, e de onde serão extraídos os recursos para sua implementação" (RODRIGUES, 2011, p. 50). Geralmente podemos estruturar o ciclo de políticas públicas conforme as seguintes etapas: 1 - Identificação do problema; 2 - Formação de uma agenda; 3 - Formação de alternativas; 4 - Tomada de decisão; 5 - Implementação; 6 - Avaliação; 7 - Extinção da política pública.

As políticas públicas podem contribuir bastante para tomada de decisões dos gestores públicos, uma vez que através dessas políticas públicas se planeja onde e como será a intervenção e a aplicação dos recursos públicos.

\section{Análise e Discusão dos Resultados}

Os Conselhos Municipais de Juazeiro-Ba foram criados entre os anos de 1990 e 2016, o Conselho de Saúde através da Lei $\mathrm{n}^{\circ}$ 2.242/2011, o de Assistência Social pela Lei $\mathrm{n}^{\circ}$ 1.446/1996 e alterado pela Lei no 2.243/2011, já o Conselho dos Direitos da Criança e do Adolescente foi instituído pela Lei ${ }^{\circ} 1.241 / 1991$ e alterado pela Lei ${ }^{\circ} 1.979 / 2008$, Conselho da Juventude pela Lei $\mathrm{n}^{\mathrm{o}} 1.835 / 2005$ e alterado pela Lei $\mathrm{n}^{\mathrm{o}} 1.983 / 2008$ e o Conselho de Educação por meio da Lei $n^{\circ} 1.609 / 2000$ e alterada pela Lei $n^{\circ} 1.890 / 2006$, Conselho Municipal de Mobilidade, Acessibilidade, Trânsito e Transporte criado pela Lei 2.636 - 26.07.2016. De 
Id on Line Revista Multidisciplinar e de Psicoloqia

Id on Line Multidisciplinary Journal and Psycology

início, foram constituídas comissões para discussão e elaboração de proposta de anteprojeto de criação de conselho, apresentada ao Prefeito que encaminhou o anteprojeto ao Poder Legislativo para após discussão, ser transformado em lei. Depois da criação, houve a formação da composição dos conselhos, elaboração e aprovação do Regimento Interno. Em relação à escolha dos representantes governamentais e da sociedade civil, esta ocorre em sua grande maioria por meio de indicação. De acordo com informações repassadas pelos conselhos municipais, a escolha dos representantes da sociedade civil se dá por meio do envio de ofício para as entidades que, por sua vez, indicam seus representantes.

Atualmente Juazeiro - Bahia tem 26 (vinte e seis) conselhos sendo alguns paritários e outros não, $70 \%$ destes conselhos encontram-se instalados em um único lugar, chamado de casa dos conselhos. A instalação fixa foi cedida pelo Poder Público Municipal, apresenta boa estrutura física com condições básicas para o funcionamento dos conselhos municipais e o governo trabalha para que $100 \%$ funcionem nesta casa.

Porém destes conselhos 21(vinte e um) estão ativos. E 05 (cinco) O CMDE - Conselho de Desenvolvimento Econômico em análise, o CMSP - Conselho Municipal de Segurança Pública em estudo, o COMCIDADE - Conselho Municipal da Cidade será empossado dia 05.08.2016 o mesmo teve sua composição alterada pela Lei 2.637/2016, o CMDC - Conselho Municipal Defesa do Consumidor em implantação e o CMATT - o último a ser criado encontrase na Câmara de vereadores para composição. Segundo o entrevistado Roosevelt Duarte Mota, Coordenador da Casa dos Conselhos, o perfil dos representantes da sociedade civil que mais de $60 \%$ são homens; em relação ao nível de instrução $50 \%$ possui o $3^{\circ}$ grau, não tendo nenhum caso de instrução inferior ao $2^{\circ}$ grau; quanto a profissão $50 \%$ estudantes e autônomos e os outros $50 \%$ restantes são distribuídos em profissões diversas; quanto a instituição representada no conselho, $50 \%$ são representantes de associações, $40 \%$ de igrejas evangélicas e católicas e $10 \%$ pelos sindicados. Observa-se que a representação das entidades religiosos nos conselhos foi maior que a representação sindical.

No que diz respeito ao tempo de participação dos representantes da sociedade civil nos conselhos municipais, $40 \%$ dos conselheiros participam há 2 anos; $40 \%$ há 3 anos; enquanto 10\% estão há 4 anos e 10\% há 5 anos. Nota-se a pouca renovação de conselheiros, porém, cabe ressaltar que alguns dos conselhos pesquisados realização renovações de conselheiros em 2016. 
Id on Line Revista Multidisciplinar e de Psicoloqia

Id on Line Multidisciplinary Journal and Psycology

Essa pouca rotatividade dos representantes da sociedade civil representa aspectos positivos e negativos.

Com a permissão de alguns conselheiros, efetuamos algumas indagações, em relação ao funcionamento dos conselhos e de sua participação no mesmo.

Segundo Silva, Bredemeir e Valenzuela (2006) o aspecto positivo seria as experiências adquiridas nos conselhos que ampliam as possibilidades de participação ativa desses representantes. E o aspecto negativo é o desenvolvimento de ações burocráticas e conservadoras.

\section{Considerações Finais}

Esta análise apresenta diversas interpretações da participação social no município de Juazeiro-Bahia, a partir dos diferentes meios oferecidos na cidade de Juazeiro-Bahia para que a sociedade tenha acesso aos eixos de deliberação sobre políticas públicas. $\mathrm{O}$ debate estabelecido facilitou compreender as diferentes maneiras de explicar a participação social, passando por princípios que apontam o nível de comprometimento dos cidadãos nos processos de tomada de decisão e permitindo observar a importância das mobilizações sociais para a conquista de meios que alcançasse a sociedade dos processos de construção e fiscalização das políticas públicas.

A participação nos conselhos municipais em Juazeiro-Bahia segundo observação não é mais efetiva devido à falta de interesse da própria comunidade, pois não acredita mais nos políticos.

Quanto à observação sobre o controle social, os representantes demonstraram clareza sobre o assunto.

Ficou visível na observação que a falta de capacitação dos conselheiros, de conhecimento sobre as atribuições em Juazeiro- Bahia compromete a capacidade de representação desses, além disso, observamos o desestimulo de alguns representantes em relação a sua atuação.

No entanto, todos os representantes indagados, tem consciência que os conselhos municipais são importantes espaços para a prática da cidadania. 
Entende-se nitidamente, que as melhorias conseguidas com a entidade dos órgãos de controle social, como os conselhos municipais, foram fundamentais para que houvesse o comprometimento direto da sociedade civil organizada nas ações da política local, no entanto, sinalizam-se algumas limitações como: a falta de conscientização da população sobre os órgãos de controle, representantes da sociedade civil incrédulo com sua atuação nesses espaços e sem estímulo para preconizar e buscar mudanças, iniciativas deficientes do poder público para motivar, mobilizar e valorizar a participação social, entre outras.

Ficou claro que a participação da sociedade civil nos conselhos em Juazeiro-Bahia ainda é apática.

Conselhos Municipais de Juazeiro-Bahia são espaços de participação popular importantíssimo para o aprofundamento da democracia, isso só poderá ocorrer na medida em que permitam que os cidadãos tenham um canal de diálogo com o Gestor Municipal e monitorem as atividades públicas municipais e toda forma, há ainda a necessidade de aperfeiçoá-los para que se tornem mais perceptíveis e dedicados.

Os motivos que levam a essa realidade são vários, desde a falta de compromisso do Gestor Público, até a falta da cidadania do povo que integram a sociedade.

Os resultados são importantes para que gestores, conselheiros, sociedade civil e pesquisadores analisarem e aprimorar o conhecimento sobre os conselhos municipais de Juazeiro-Bahia.

\section{Referências}

ANDRADE, Gabriela Rieveres Borges de, VAITSMAN, Jeni. A participação da sociedade civil nos conselhos de saúde e de políticas sociais no município de Piraí, RJ (2006). Ciência \& Saúde Coletiva. V.18 n. 7, 2013, Rio de Janeiro p.2059-2068.

BENELLI, Silvio José, ROSA, Abílio da Costa. Conselhos municipais: prática e impasses no cenário contemporâneo. Psicologia em Estudo. V. 17, n. 4, 2012 Maringá p. 577-586.

BRASIL, Constituição (1988). Constituição da República Federativa do Brasil: texto constitucional promulgado em 5 de outubro de 1988, com as alterações adotadas pelas Emendas constitucionais $n^{\circ}$ s $1 / 1992$ a 88/2015, pelo Decreto legislativo $n^{\circ} 186 / 2008$ e pelas Emendas constitucionais de revisão n's 1 a 6/1994 
Id on Line Revista Multidisciplinar e de Psicoloqia

Id on Line Multidisciplinary Journal and Psycology

GOMES, Eduardo Granha Magalhães. Conselhos gestores de políticas públicas: aspectos teóricos sobre o potencial e controle social democrático e eficiente. Cadernos EBAPE.BR, V.13, n.4, 2015, Rio de Janeiro p.894-909.

KLEBA, Maria Elisabeth, COMERLATTO, Dunia, FROZZA, Kenia Munaretti. Instrumentos e mecanismos de gestão: contribuição ao processo decisório em conselhos de políticas públicas. Revista de Administração Pública. V.49 n. 4, Rio de Janeiro p. 10601079.

LACERDA, Norma, MARINHO, Geraldo, BAHIA, Clara, QUEIROZ, Paulo, PECCHIO, Rubén. Planos diretores municipais: aspectos legais e conceituais. Revista Brasileira de Estudos Urbanos e Regionais. V. 7, $\mathrm{n}^{\circ}$ 1, 2005 p. 55-72. Disponível << http://unuhospedagem.com.br/revista/rbeur/index.php/rbeur/article/view/135 >> acesso: 25.07.2016.

MORONI, José Antônio. O direito à participação no governo Lula. In: AVRITZER, Leonardo [org.]. Experiências nacionais de participação social. São Paulo: Cortez, 2009. (Coleção Democracia Participativa). Disponível:

$<<$ http://www.portalconscienciapolitica.com.br/products/politicas-publicas-e-processos-degestao/>> acesso: 25.07.2016

RODRIGUES, Marta M. Assumpção. Políticas Públicas. São Paulo: 2011. (Coleção Folha Explica). Disponível em: << http://www.portalconscienciapolitica.com.br/ci\%C3\%AAnciapolitica/politicas-publicas/ > acesso: 25.07.2016

SECCHI, Leonardo. Políticas Públicas: conceitos, esquemas de análises, casos práticos. São Paulo: CENGAGE Learning, 2012. Disponível em:

$<<$ http://www.portalconscienciapolitica.com.br/products/politicas-publicas-e-processos-degestao/> $>$ acesso:25.07.2016

SOUZA, Celina. Políticas Públicas: uma revisão da literatura. Sociologias. Ano 8, nº 16, 2006 Porto Alegre, p.20-45.

TATAGIBA, Luciana. Conselhos gestores de políticas públicas e democracia participativa: aprofundando o debate. Revista de Sociologia e Política. n. 25, 2005 Curitiba p. 209-213.

Como citar este artigo (Formato ABNT):

BATISTA, I U.; NASCIMENTO, D.C. A Participação da Sociedade Cívil nos Conselhos Municipais em Juazeiro - Bahia: Prática de Cidadania. Id on Line Revista Multidisciplinar e de Psicologia, Outubro de 2016, vol.10, n.31, p. 178-191. ISSN 1981-1179.

Recebido: 15/08/2016.

Aceito: 18/08/2016 